\title{
TEXTO E CONTEXTO
}

\author{
Leci Borges Barbisan
}

RESUMO: Ce petit article étudie la relation entre le texte et son contexte sous la lumière de la Linguistique Textuelle à partir du travail de M. A. K. Halliday paru dans son ceuvre Language, Context and Texte (1989). Le texte de Luís Fernando Veríssimo Experiência nova paru dans le quotidien Zero Hora le 4 avril 1993 y est analysé en vue d'une brève revision critique de la théorie.

PALAVRAS-CHAVE: texto, contexto, sentido, discurso.

O objetivo deste trabalho é o de discutir o conceito de contexto conforme a linha de estudos da Lingüística do Texto. Para tanto, estaremos apresentando o trabalho proposto por Halliday, sobre esse tema, nos primeiros capítulos de seu livro em co-autoria com Ruqaiya Hasan, Language, Context and Text (1989). Os conceitos teóricos de Halliday serão aplicados à crônica de Luís Fernando Veríssimo, Experiência nova, publicada em Porto Alegre, na última página da Revista ZH da edição dominical do jornal Zero Hora, em 4 de abril de 1993. Após a aplicação, alguns comentários serão feitos a respeito da teoria.

\section{A PROPOSTA DE HALLIDAY}

Em sua obra, Halliday propõe uma abordagem da linguagem que focaliza o semiótico, o social e o funcional. É necessário que fique definido primeiramente o que Halliday entende com esses termos. É preciso que se explique ainda como se apresentam os conceitos de texto e de contexto nessa perspectiva.

O termo semiótica designa, não o estudo do signo inicialmente isolado, como uma entidade, e depois relacionado com outros signos, mas o estudo dos sistemas de signos numa rede de relações, o que conduz ao estudo do significado de modo amplo. Uma série de sistemas semióticos constitui a cultura, vista como uma série de sistemas de significados inter-relacionados. A linguagem é apenas um dentre muitos outros sistemas de sentido que constituem a cultura humana. 
Com o termo social, Halliday designa primeiramente um sistema social, uma cultura. Em segundo lugar, numa interpretação mais específica, social indica relações entre linguagem e estrutura social, considerando a estrutura social como um aspecto do sistema social. A perspectiva adotada por Halliday para estudar a linguagem é relacionada com esse aspecto particular da experiência humana que é a estrutura social.

O modo de entender a linguagem reside no estudo do texto. Texto é linguagem funcional, quer dizer, linguagem que desempenha um papel em um contexto. Há o texto e há outro texto que o acompanha, o contexto, que vai além do que é dito e escrito, e inclui o não-verbal, o quadro total no qual o texto se desenvolve e onde deve ser interpretado. Um texto é feito de sentidos, é uma unidade semântica. Como tal, deve ser considerado de duas perspectivas: como produto e como processo. Como produto é resultado e tem uma construção que pode ser representada sistematicamente. É processo no sentido de escolha semântica contínua na rede de significados potenciais, em que cada escolha constitui o contexto para a série seguinte.

$\mathrm{Na}$ perspectiva sócio-semiótica, o texto como processo é visto como um acontecimento interativo, como troca social de significados. Texto é troca, é interação entre falantes. Como produto, texto é objeto no sentido próprio, é instância de significado social num contexto particular de situação. É um produto de seu contexto, produto de um contínuo processo de escolhas no significado, escolhas representadas nas redes que constituem o sistema lingüístico. O contexto de situação está contido no texto através de uma relação sistemática entre o contexto social de um lado e a organização funcional da linguagem de outro lado.

Para interpretar o contexto social de um texto, Halliday propõe três conceitos: campo, teor e modo. O campo do discurso é o que está acontecendo, a natureza da ação social, aquilo em que os participantes estão engajados. O teor refere ao status dos participantes, ao seu papel, às relações temporárias e permanentes que há entre eles. $\mathrm{O}$ modo diz respeito a que parte a linguagem está representando, o status do texto e sua função no contexto, incluindo o canal (oral e escrito), o retórico, o que está sendo realizado pelo texto em termos de categorias como persuasivo, expositivo, didático, etc.

Campo, teor e modo estão expressos por traços lingüísticos particulares. Assim, o campo se faz notar no vocabulário, por exemplo. O teor, na noção de pessoa, na escolha da função da fala: ordem, oferta, etc., que se traduzem pelo uso de imperativos, de funções declarativas e outros. O modo aparece na escolha dos temas, em traços léxico-gramaticais específicos à língua oral ou à escrita, no uso de conjunções ou outro tipo particular de coesão.

Segundo Halliday, é esse o modo como as pessoas fazem predições. Constrói-se na mente um modelo de contexto de situação. Atribui-se-lhe campo, notando o que está acontecendo, teor, reconhecendo as relações pessoais envolvidas, e modo, vendo o que está sendo realizado por meio da linguagem. Os participantes de uma cultura fazem uso da relação estreita entre texto e situação, da 
correlação entre traços do texto e traços da situação como base para sua interação.

Para se entender melhor esse fato, Halliday apresenta o conceito de registro: uma variedade de linguagem corresponde a uma variedade de situação. Registro é um conceito semântico, configuração de significados que são tipicamente associados com uma configuração situacional particular de campo, teor e modo. Os traços léxico-gramaticais e fonológicos indicam aos participantes a presença do registro em questão. Os traços textuais tornam o discurso coerente com ele mesmo e também com o conceito de situação. Há redundância entre texto e situação, um serve para predizer o outro.

Diferentemente de lingüistas como Malinowski, Bühler, Morris e outros que definem função como uso da linguagem para diferentes propósitos de comunicação em termos não-lingüísticos, vendo a linguagem de fora, Halliday propõe que se dê um passo à frente e se entenda função não como o uso da linguagem, mas como uma propriedade fundamental da própria linguagem, algo que é básico para a evolução do sistema semântico.

Para analisar um texto, é necessário olhar seu significado como representação de algum tipo de processo, acontecimento ou estado do mundo real. Certos traços do texto representam o mundo real como apreendido por nossa experiência. Isso mostra o sentido experiencial do texto. Acrescente-se a isso a representação imaginativa ou oblíqua da experiência, que constitui o metafórico.

Mas o texto não é só uma representação da realidade. É também um modo de interação entre falante e ouvinte. É um modo de agir que define o significado do interpessoal, no processo de interação social.

Além disso, propõe Halliday, há nas línguas naturais uma rede de relações lógicas fundamentais, expressas como as diferentes formas de parataxe e hipotaxe. Esse aspecto da linguagem define o significado textual, ou seja, a textura.

Há quatro aspectos do significado: o experiencial, o interpessoal, o lógico e o textual. Cada sentença num texto não tem só um tipo de significado, mas é multifuncional.

Existe relação sistemática entre campo e função experiencial. O teor é expresso pela função interpessoal e o modo se manifesta através da função textual.

O contexto de situação, analisado em seus três componentes (campo, teor e modo), correspondendo a três metafunções (referencial, interpessoal e textual), é o contexto imediato no qual o texto funciona. Explica-se assim por que certas coisas são ditas ou escritas em ocasiões particulares.

Mas há outro contexto, mais amplo, que é o contexto de cultura. As pessoas dizem certas coisas em determinadas ocasiões e atribuem significados e valores a elas, de acordo com o meio cultural em que vivem.

A relação texto-contexto é dialética. $\mathrm{O}$ texto cria o contexto assim como o contexto cria o texto. Da relação entre os dois surge o significado. Parte do contexto é uma série de textos prévios compartilhados entre os participantes. Este é um tipo de intertextualidade que inclui não só os traços mais obviamente experienciais, mas também outros aspectos do significado: tipos de seqüências 
lógicas e até traços interpessoais.

Halliday entende que todo texto tem coerência, se mantém unido e coeso. $\mathrm{O}$ que vem antes fornece o contexto ao que vem depois. Há expectativas internas e estas têm a ver com as externas: contexto de situação e de cultura.

Resumindo-se a proposta de Halliday, cinco considerações devem ser feitas na relação texto-contexto:

1. um texto é um complexo de significados referenciais, interpessoais e textuais;

2. o contexto de situação é a configuração de campo, teor e modo, traços que especificam o registro do texto;

3. o contexto de cultura é o quadro institucional e ideológico que dá valor ao texto e limita sua interpretação;

4. o contexto intertextual é constituído pelas relações com outros textos e afinnações que são feitas a partir daí;

5. o contexto intratextual é a coerência dentro do texto, incluindo a coesão lingüística que compreende as relações semânticas internas.

\section{ANÁLISE}

Vai-se tentar seguir de perto a proposta de Halliday, aqui apresentada, para o estudo do contexto, analisando o texto de Luis Fernando Veríssimo, Experiência nova.

Em seu escrito, que pode ser enquadrado no gênero crônica, o autor apresenta um diálogo entre dois protagonistas: um delegado de polícia e um ladrão de galinhas. O diálogo é interrompido algumas vezes pelo narrador para relatar a evolução da atitude do delegado em relação ao ladrão.

Os três conceitos de campo, teor e modo devem permitir fazer a descrição situacional do texto. Quanto ao campo, trata-se de um texto de caráter lúdico em que o autor conta um fato que se inscreve no domínio do policial: a história de um ladrão de galinhas. O campo, diálogo policial, aparece refletido no vocabulário, na nomeação de processos tais como roubar, especular, superfaturar, sonegar, depositar ilegalmente, e na designação de participantes: delegado de polícia, ladrão. Aparece ainda o uso de palavras como venda de artigo roubado, drogas, coisa proibida, castigo, cadeia, que apontam para dois motivos: o da ação ilegal e o da censura dessa ação, com sua conseqüente punição.

O teor indica que os participantes do discurso são um delegado de polícia e um ladrão. É um diálogo entre ambos, se passa numa delegacia, e consiste na investigação dos furtos praticados pelo ladrão. O delegado é a autoridade que representa a lei, enquanto o ladrão é o delinqüente. Mas esse diálogo foi escrito e publicado pelo autor, Luis Fernando Veríssimo, conhecido escritor e humorista, que aqui é um cronista e tece comentários a respeito de determinadas situações para o público leitor do jornal, especialmente para aqueles que apreciam ler seus 
escritos. O texto tem então um teor secundário, o de um cronista dirigindo-se a seus contemporâneos.

O teor é expresso por meio de traços lingüísticos como o cara, vagabundo, sem-vergonha, safado, pilantra, tu, você, o preso, doutor, o senhor, excelência, para designar o ladrão. O delegado é nomeado como delegado pelo narrador. No diálogo entre delegado e ladrão, este não o nomeia, presta apenas os esclarecimentos exigidos. Percebe-se, então, na relação interpessoal, a hierarquia claramente definida pela função de fala de pedido de esclarecimento do delegado, a quem é atribuído o estatuto autoritário, e a função de fala de prestação de esclarecimentos do ladrão a quem somente isso é permitido.

$\mathrm{O}$ modo se refere à linguagem. É um texto escrito, que imita um diálogo oral, com alguns traços de língua falada, mesclados com características de língua escrita, lembrando diálogos de romance ou de teatro. As intervenções do ladrão contêm uma narrativa, que pode ser percebida no que conta o ladrão a respeito de suas aventuras.

Outra questão a considerar quanto ao modo é a escolha temática. Observando-se globalmente, passa-se do roubo de galinhas ao comércio de ovos e galinhas, à aplicação dos lucros, à aventura de roubar e à possibilidade de punição. A relação entre roubo, censura e punição se coloca desde o início e evolui, chegando a se anular quando a revelação das ações fraudulentas do ladrão se tornam mais numerosas e mais sofisticadas. Essa relação roubo-censura-punição é o tema central da crônica.

Uma análise de Experiência nova, do ponto de vista funcional, deve ser feita com relação aos significados experiencial, interpessoal, lógico e textual.

Quanto ao seu significado experiencial, o texto relata acontecimentos, ações, estados, lugares que representam fenômenos do mundo real. É um modo de pensar a realidade. Há agentes como o ladrão, o dono do galinheiro, o delegado de polícia. Há processos realizados por roubar, vender, fazer um acerto, especular, investir, sonegar, etc. Encontram-se elementos circunstanciais como locativos: vai pra cadeia, o dinheiro depositado no exterior, e também nomes de coisas usados após um processo, casos de roubar galinhas, botar ovos brancos, aumentar os preços.

Todos esses traços representam o mundo real como ele é apreendido em nossa experiência. Mas, ao lado deles, há ainda, no texto, representações imaginativas ou oblíquas da experiência; elas são metafóricas e envolvem transferência. Seria um exemplo comprei alguns deputados, onde o significado da ação transita para um nome de ser animado humano quando seria de se esperar um nome de ser inanimado ou não-humano. Não há outra metáfora no texto, que parece ser essencialmente uma representação do mundo real.

Considerando-se a função de interação social, isto é, o significado interpessoal do texto, seria necessário ver nele a relação entre falante e ouvinte. Essa interação dá-se, neste caso, em duas dimensões. Internamente, delegado e ladrão dialogam. Há, na fala do delegado, sentenças que são perguntas, solicitações 
de esclarecimentos mescladas com sentenças avaliativas de censura. Na fala do ladrão, percebem-se sentenças declarativas, respostas que satisfazem ao pedido de esclarecimento, juntamente com sentenças com função de protesto diante da indulgência do delegado. Esse diálogo é interrompido em determinados momentos por uma outra interação, constituída pela fala de apenas um dos participantes. É um monólogo: o de um narrador onisciente que, por meio de sentenças declarativas, explica a transformação da atitude do delegado em relação ao ladrão.

Externamente, seria interessante considerar a interação autor-leitor. O autor narra, através de um diálogo, a história de um ladrão. O interlocutor dessa narrativa é o leitor da crônica que, evidentemente, não participa da interação, já que se trata de um texto escrito, mas que deve ser previsto pelo autor, que a ele dirige seu texto.

O significado lógico se traduz pelas relações de coordenação e subordinação entre partes do texto. Encontram-se, na crônica em estudo, principalmente coordenações com mas e $e$. Mas, utilizado tanto pelo ladrão quanto pelo delegado, quanto ainda pelo narrador, tem a função de contestar a afirmação anterior. É o caso da intervenção do ladrão ao dizer que não fazia concorrência desleal ao comércio estabelecido porque vendia mais caro seus produtos. $\mathrm{O}$ delegado, por sua vez, contesta, com mas, a pressuposição inferida de que eram as mesmas galinhas, as do galinheiro e as do ladrão. O mas do narrador modaliza as exclamações de avaliação negativa do delegado, indicando a mudança de atitude deste no que diz respeito às ações do ladrão.

A coordenativa $e$ articula partes do texto com funções de fala da mesma classe, como acontece na intervenção do narrador que coordena com $e$ duas sentenças declarativas. É ainda o caso da articulação por $e$ de sentenças também declarativas do ladrão.

Quanto ao significado textual, há o equilíbrio do ponto de vista semântico entre pedidos de esclarecimento feitos pelo delegado e asserções como satisfações a esses pedidos, de parte do ladrão. Quanto ao aspecto gramatical, a relação entre perguntas e respostas parece constituir a textura da crônica.

Os elementos até aqui levantados no texto em análise referem-se ao seu contexto imediato. $\mathrm{O}$ outro contexto de que fala Halliday é o cultural. $\mathrm{O}$ texto de Luis Fernando Veríssimo está inscrito numa cultura em que o roubo é punido. Assim, o delegado de polícia representa a autoridade a quem a sociedade atribui o papel e o poder de fazer cumprir a lei e de punir quem a transgredir. A autoridade tem seu status, que se percebe no texto pelo tratamento de desprezo e pelos insultos que o delegado dirige ao ladrão. Este aceita, sem protestar, tal tipo de tratamento, reconhecendo implicitamente a lei e sua posição de infrator. Está-se diante de uma norma social que defende o direito de propriedade e pune quem desrespeita esse direito, assim como pune outras infrações como tráfico de drogas, suborno, estelionato. O conhecimento dessas normas culturais é compartilhado pelo autor e pelo seu leitor que, desse modo, pode apreender significados a partir do texto. 


\section{POSIÇÃO CRÍTICA}

Entretanto, a questão que se coloca é a de como, a partir desses princípios culturais, o leitor dessa crônica consegue produzir sentido se, à medida que se desenvolve a narrativa e aumentam e se agravam os delitos do ladrão, vê-se uma diminuição na severidade do delegado, se modifica substancialmente a relação delegado-ladrão, surgindo condescendência de parte da autoridade para com o infrator, chegando ao ponto de desaparecer a possibilidade de punição. Esses fatos contrariam a cultura e acabam por criar incongruência e nonsense.

Parece então que o chamado contexto cultural não dá conta do sentido da crônica, considerando-se, como quer Halliday, que há relação direta e estreita entre texto e contexto. Aqui o texto estaria contrariando o contexto cultural.

Poder-se-ia objetar que se está em presença de um discurso que se serve de procedimentos irônicos como estratégia argumentativa e que, assim sendo, afirma o contrário daquilo que quer defender (definição de ironia com a qual, sabese, dificilmente se pode concordar integralmente). Admitindo-se a ironia, que realmente existe nesse texto, ainda assim a questão não ficaria resolvida, porque então se perguntaria: por que o recurso à ironia? Que sentido ela assume no texto? Por que o autor se serve dessa estratégia para defender um ponto de vista cultural compartilhado pelo leitor-destinatário, participante do ato de linguagem, inseridos ambos na mesma cultura? Isso não estaria em contradição com a primeira condição de adequação (CHAROLLES, 1980), segundo a qual um locutor só faz uma argumentação para convencer seu interlocutor sobre alguma coisa se ele pensa que este último, até o momento da enunciação, não acredita naquilo sobre o que ele está argumentando?

Para se encontrar uma solução à questão levantada, torna-se indispensável apelar para a noção de condições de produção, não prevista pela proposta de Halliday. Entende-se, com Courtine (1980), as condições de produção alinhadas à análise histórica das contradições ideológicas presentes nos discursos e articulada ao conceito deformações discursivas.

Para dar coerência ao texto em estudo e esclarecer seu sentido, deve-se fazer apelo ao momento de sua produção (abril de 1993), quando ações altamente controvertidas, do ponto de vista cultural, quanto à integridade de personalidades do alto escalão governamental eram reveladas à nação através dos diferentes meios de comunicação, e nenhuma medida de punição era tomada como seria esperado social e culturalmente.

Entende-se então que, diante de fatos dessa ordem, que estariam numa cultura que se caracterizaria como discriminante e permissiva, o autor tome posição contra ela, posição que se torna a chave do sentido do texto em questão.

Vendo-se $o$ ato de linguagem sob essa perspectiva, outras questões teóricas aparecem, e que não coincidem com a proposta de Halliday. Uma delas é a de que o sentido não é mais entendido como o resultado de um processo interacional entre dois sujeitos empíricos, um eu e um $t u$, que compartilham 
conhecimentos de mundo e experiências, e em que o eu é o onipotente dono da linguagem e fonte do sentido. Do ponto de vista que aqui se propõe, há um sujeito que se inscreve numa determinada formação discursiva. $O$ sentido não é, então, determinado pela referência que a linguagem faz ao mundo, mas é definido pela relação do sujeito com o ideológico. É o que se evidencia nesta crônica, na qual não são os fatos reais narrados pelo ladrão que determinam o sentido do texto, mas as relações que se estabelecem entre elementos do saber de formações discursivas antagônicas, marcando a posição que o sujeito assume em seu discurso. A própria ironia que se percebe na crônica decorre desse antagonismo e assim se explica.

Outra questão que se coloca é a de que não se trata de um sujeito único, individual, do qual se quer que emane o sentido, como se depreende da perspectiva de análise do contexto estabelecido por Halliday, mas de uma interdiscursividade, que cria efeitos de sentido. Várias vozes dialogam, a partir de lugares diferentes, nessa crônica. E é nesse rumor polifônico, em que predominam relações de antagonismo entre essas vozes que se sedimenta o sentido.

\section{CONCLUSÃO}

Concluindo, seria possível afirmar-se que a proposta de Halliday (1989) para explicar a importância do contexto na definição do sentido não parece plenamente satisfatória. Os componentes do contexto imediato - campo, teor e modo - e suas relações com as funções experiencial, interpessoal e textual denotam apenas os significados referenciais e as relações compartilhadas no contexto de comunicação entre os sujeitos empíricos $e u$ e $t u$. O contexto cultural coloca os protagonistas e o próprio ato de linguagem numa rede de relações, num contexto mais amplo, mas que limita a interpretação do texto.

Como se viu, ao se fazer a breve análise da crônica de Luís Fernando Veríssimo, a teoria de Halliday para o contexto não explica o sentido do texto. Torna-se então oportuno buscar soluções nas condições de produção, nas formações ideológicas e discursivas e na pluralidade de vozes que estão na origem dos efeitos de sentido que se produzem no discurso. 


\section{ANEXO}

\section{Experiência nova}

Pegaram o cara em flagrante roubando galinhas de um galinheiro e levaram para a delegacia.

- Que vida mansa, hein, vagabundo? Roubando galinha pra ter o que comer sem precisar trabalhar. Vai pra cadeia!

- Não era pra mim não. Era pra vender.

- Pior. Venda de artigo roubado. Concorrência desleal com o comércio estabelecido. Sem-vergonha!

- Mas eu vendia mais caro.

- Mais caro?

- Espalhei o boato que as galinhas do galinheiro eram bichadas e as minhas não. E que as do galinheiro botavam ovos brancos e as minhas botavam ovos marrons.

- Mas eram as mesmas galinhas, safado.

- Os ovos das minhas eu pintava.

- Que grande pilantra...

Mas já havia um certo respeito no tom do delegado.

- Ainda bem que tu vai preso. Se o dono do galinheiro te pega...

- Já me pegou. Fiz um acerto com ele. Me comprometi a não espalhar mais boato sobre as galinhas dele, e ele se comprometeu a aumentar os preços dos produtos dele para ficarem iguais aos meus. Convidamos outros donos de galinheiro a entrar no nosso esquema. Formamos um oligopólio. Ou, no caso, um ovigopólio.

- E o que você faz com o lucro do seu negócio?

- Especulo com dólar. Invisto alguma coisa no tráfico de drogas. Comprei alguns deputados. Dois ou três ministros. Consegui a exclusividade no suprimento de galinhas e ovos para os programas de alimentação do governo e superfaturo os preços.

- O delegado mandou pedir um cafezinho para o preso e perguntou se a cadeira estava confortável, se ele não queria uma almofada. Depois perguntou:

- Doutor, não me leve a mal, mas com tudo isso, o senhor não está milionário?

- Trilionário. Sem contar o que eu sonego do Imposto de Renda e o que tenho depositado ilegalmente no exterior.

- E, com tudo isso, o senhor continua roubando galinhas?

- Às vezes. Sabe como é.

- Não sei não, excelência. Me explique.

- É que, em todas essas minhas atividades, eu sinto falta de uma coisa. Do risco, entende? Daquela sensação de perigo, de estar fazendo uma coisa 
proibida, da iminência do castigo. Só roubando galinhas eu me sinto realmente um ladrão, e isso é excitante. Como agora. Fui pego, finalmente. Vou para a cadeia. É uma experiência nova.

- O que é isso, excelência? O senhor não vai ser preso não.

- Mas fui pego em flagrante pulando a cerca do galinheiro!

— Sim. Mas primário, e com esses antecedentes...

\section{BIBLIOGRAFIA}

CHAROLLES, M. Les formes directes et indirectes de l'argumentation. Pratiques, n.28, oct. 1980.

COURTINE, J.-J. Quelques problèmes théoriques et méthodologiques en Analyse du Discours à propos du discours communiste adressé aux chrétiens. Université de Paris X- Nanterre, 1980. (tese de $3^{\circ}$ ciclo).

HALLIDAY, M. A. K. \& HASAN, R. Language, context and text. Oxford, Oxford University Press, 1989.

VERÍSSIMO, L. F. Experiência nova. Zero Hora, 4 abr. 1993. 
Perspectiva da Enunciação 
